\title{
Comparisons of sampling methods and seasonal abundance of Drosophila repleta in caged-layer poultry houses
}

\author{
L. C. HARRINGTON and R. C. AXTELL \\ Department of Entomology, North Carolina State University, Raleigh, North Carolina, U.S.A.
}

\begin{abstract}
Four sampling methods were compared to determine their practicality and suitability for detecting population fluctuations of adult Drosophila repleta, a pest in caged-layer poultry houses. Five caged-layer poultry houses with gutter-flush manure removal systems in Franklin County, North Carolina, U.S.A., were sampled once every 2 weeks over 15 months, from June 1991 to August 1992 . The flies were most abundant during the spring and early summer. Visual counts of adult flies resting on the feed troughs in front of cages in the aisles and counts of flies caught on a sticky ribbon lowered into the gutter used for manure removal by flushing were more satisfactory sampling methods than using counts of flies caught on sticky ribbons carried along the aisles or aspirator collections from the gutters. For the visual count method, the effects of location in the house, within each aisle, and feed trough height were determined; two counts on feed troughs in each of two inside rows of cages were sufficient to measure population changes. For routine monitoring of D.repleta populations, visual counts of flies resting on the feed troughs in the front area of two aisles and catching flies on sticky ribbons inserted into the rear gutter area are recommended.
\end{abstract}

Key words. Drosophila repleta, Diptera, Drosophilidae, fruit flies, sampling methods, poultry houses, manure, U.S.A.

\section{Introduction}

Drosophila (commonly known as fruit flies) may be extremely abundant and a nuisance in caged-layer poultry houses as well as other confined-animal facilities. Because they breed in manure and the adults rest on the animal feed and equipment, these flies are potential carriers of pathogens. Based on our observations and collections, the predominant species found in caged-layer houses in North Carolina, U.S.A., is Drosophila repleta Wollaston (1858); we have also collected it from turkey and swine facilities. This species is cosmopolitan. Farkas \& Papp (1989) reported the incidence of high numbers of D.repleta in a caged-layer house in Hungary. It is a pest in swine facilities and cattle barns in Europe (Kuhlhorn, 1964; Papp, 1974;

Correspondence: Dr R. C. Axtell, Department of Entomology, Box 7613, North Carolina State University, Raleigh, NC 276957613, U.S.A.
Ribbeck et al., 1987), and a significant nuisance in swine farrowing facilities in Ontario, Canada (Surgeoner, personal communication, 1992). Undoubtedly D.repleta is a major pest in livestock and poultry facilities in many parts of the world, although published data are limited.

Information on effective sampling methods as well as the behaviour and population dynamics of this fly in poultry houses is lacking. This study was conducted to evaluate sampling methods and to determine the population abundance patterns inside caged-layer poultry houses.

\section{Materials and Methods}

Sampling sites. Five caged-layer poultry houses on three farms in Franklin County, North Carolina, U.S.A., were sampled, using four methods, approximately every 14 days for 15 months (5 June 1991 to 21 August 1992) for a total of twenty-nine sampling dates. No sampling was conducted 
during December 1991 (weeks 27 and 29) because the houses were in quarantine.

All five houses were one-storey, wide-span style with the manure removed frequently by flushing with water. House A (Colbert) was $12 \times 180 \mathrm{~m}$ with four rows $(160 \mathrm{~m}$ long) of three tiers of back-to-back cages (four birds/ cage), with a shallow concrete pit beneath the cages, and a raised concrete walkway between the rows of cages. Dropping boards were located directly beneath each tier of cages. Manure dropped onto these boards and then onto the shallow pit beneath the cages. Water was pumped into the front of the house and flushed the manure in the shallow pits below the cages to the back of the house into deeper gutters and out of the house into a lagoon. The concrete gutters $(0.5 \mathrm{~m}$ deep $\times 2.0 \mathrm{~m}$ wide $)$ were located in the back of the house, below the end of each row of cages and perpendicular to the cages and aisles. This type of manure removal system is called gutter-flush.

Automatic feeders and waterers were used. Feed troughs were in front of each tier of cages for the entire length of the row. The house was well maintained and the manure removal system was operating normally.

Houses B and C on one farm (Green) were $12 \mathrm{~m}$ wide $\times$ $120 \mathrm{~m}$ long and similar to house $\mathrm{A}$. There were four rows of back-to-back cages which were in only two tiers and there were no dropping boards. Manure was removed by a gutter-flush system supplemented by a tractor-mounted scraper. The houses were improperly maintained and in poor condition. The equipment in the houses (cages, feeders, waterers) was old and damaged, manure was not removed from the house every week, and crusts of manure formed around the edges of the gutters and walkways.

Houses D and $\mathrm{E}$ on one farm (Gardner) were $12 \mathrm{~m}$ wide $\times 200 \mathrm{~m}$ long and the same design as house $\mathrm{A}$. There were four rows of back-to-back cages and five walkways. House D had four tiers of cages. Both houses had dropping
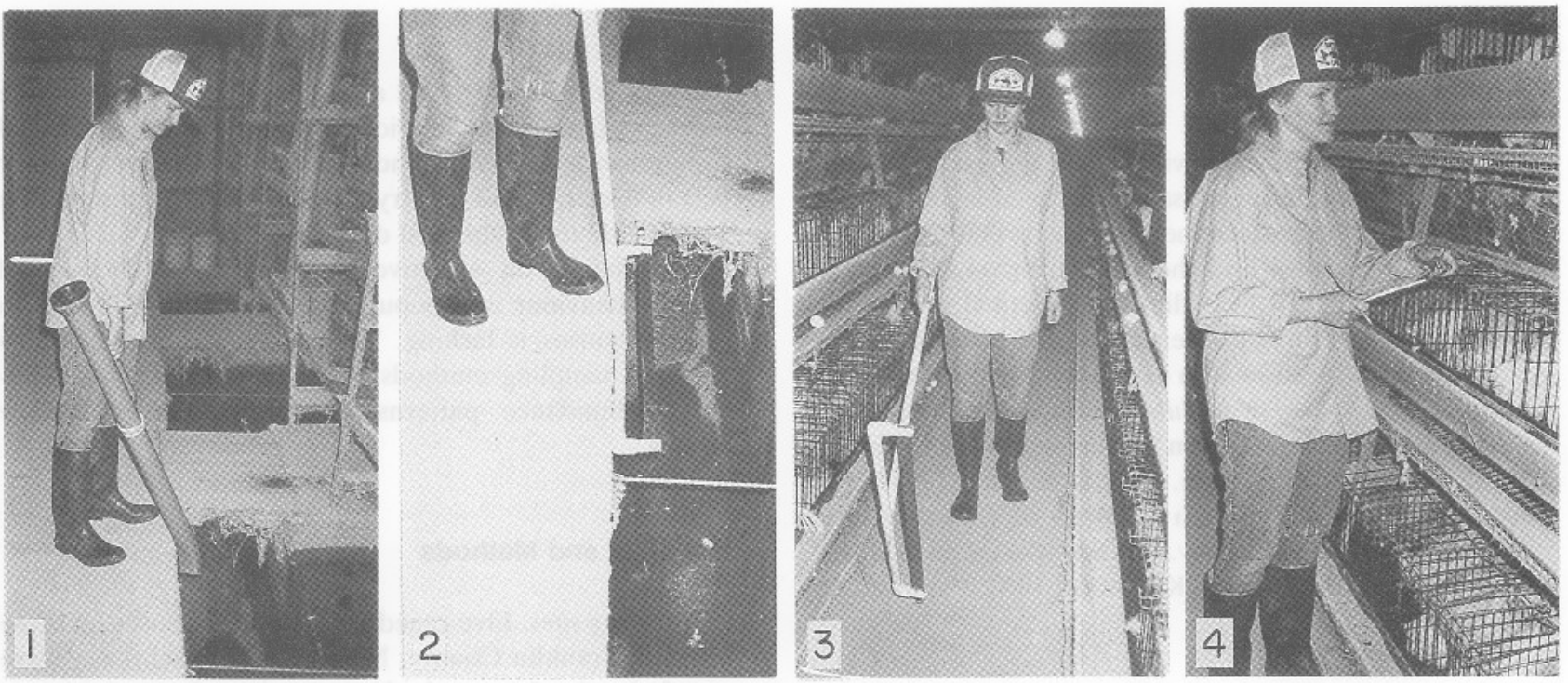

Figs 1-4. (1) Gutter aspirator collection method. (2) Sticky fly ribbon gutter collection method. (3) Sticky fly ribbon aisle collection method. (4) Visual method of counting resting flies on the outside of feed troughs in the aisle. boards below the cages, and gutters at the end of each cage row in the back of the house in the same manner as house A. House D was in excellent condition; the house, of the house every day, and feed spills rarely occurred. House E was older than house D, but in good condition and the manure removed routinely.

Sampling methods. Four sampling procedures were compared. The flies in the gutter area in the back of each house were sampled by aspirator and sticky ribbons. The flies in the aisles were sampled by walking with a sticky ribbon and visual counts of flies resting on the feed troughs.

Aspirator. A modified sweepstick battery-operated broom (Black \& Decker, Hunt Valley, Maryland, U.S.A.) was used for the aspirator method (Fig. 1). The broom was modified into an aspirator by reversing the fan and the poles on the motor to draw in air as described by Perdew \& Meek (1990). A piece of nylon netting was placed beneath the detachable plastic extension pipe to trap the aspirated flies. The nylon netting containing the aspirated flies was removed from the sweepstick, placed in a container and returned to the laboratory for sorting, identifying and counting. Each aspirator sample consisted of one slow steady sweep, for a distance of about $50 \mathrm{~cm}$, at a $15 \mathrm{~cm}$ depth along the gutter wall; four samples were taken per house.

Gutter ribbon. The gutter area was sampled with a sticky fly ribbon held in a fork made of polyvinyl chloride (PVC) plastic pipe (Fig. 2). The U-shaped fork supporting the fly ribbon was $50 \mathrm{~cm}$ across and had a $2 \mathrm{~m}$ long handle. The fly ribbon was slowly lowered $15 \mathrm{~cm}$ down into the gutter and slowly withdrawn. The Drosophila caught on the fly ribbon were counted and recorded. This method was used for each gutter at the end of each row of cages, providing a total of four counts per house.

Aisle ribbon. The same PVC pipe fork with a fly ribbon cages and feeders were new, the manure was flushed out 
was used to sample the flies in the aisles (Fig. 3). This method was similar to the moving-tape method used by Turner \& Ruszler (1989) to monitor house-fly populations in caged-layer houses. We improved the moving-tape method by attaching the tape to the PVC pipe fork so that the movement of the person walking had less of an effect on the flies in the aisle. Sampling was conducted by holding the fork straight ahead, $15 \mathrm{~cm}$ above the floor, and walking at a slow steady pace down the aisle. Counts of the number of Drosophila on $50 \mathrm{~cm}$ of fly tape were made in two inside aisles from the front to the middle of each aisle $(70 \mathrm{~m})$ and from the middle to the back $(70 \mathrm{~m})$, providing a total of four counts per house.

Visual count. The visual count method also sampled the number of flies in the aisle area of the house. The Drosophila resting on the outside surface of a $3 \mathrm{~m}$ length of feed trough were counted (Fig. 4). Flies were counted on a upper ('top') feeder (about $2 \mathrm{~m}$ above the floor) and a lower ('bottom') feeder (about $1.5 \mathrm{~m}$ above the floor); these feeder locations were the middle and top ones in houses with three-tier cages and the two middle ones in the house (D) with four-tier cages. The number of Drosophila resting on the top and bottom feeders were counted in the front, middle and back of two of the inside aisles in each house, providing a total of twelve counts per house.

Species identification. The fruit flies captured were identified as Drosophila repleta Wollaston, according to descriptions and keys by Strickberger (1962) and Patterson \& Mainland (1944). The species was recognized in routine sorting and counting of collections by the following characteristics: bristles and hairs on the mesonotum each arising from a separate dark spot and these spots often fused together; the coxae of the fore legs heavily darkened in comparison to the rest of the leg; the abdomen with distinctive yellow banding shading into brown along the lateral margins of the abdominal tergites; and pale palpi. Representative specimens were identified as D.repleta by Dr David Grimaldi, Museum of Natural History, New York City, New York, U.S.A. Voucher specimens have been deposited in the Department of Entomology Insect Collection, North Carolina State University, Raleigh, North Carolina, U.S.A.

Data ánalysis. The data were analysed by General Linear Models procedure (PROC GLM) (SAS Institute, 1988) to compare the seasonal abundance and sampling methods. The sampling methods were compared using the square root transformation of the data. The effects of seasons were examined by grouping the data into five categories corresponding to climatic conditions during the 15-month sampling period. These seasonal categories were: summer (June-August 1991, weeks 1-13), autumn (September-November 1991, weeks 15-25), winter (January-February 1992, weeks 37-38), spring (MarchMay 1992, weeks 41-52) and summer (June-August 1992, weeks 54-64). The two gutter sampling methods were compared to each other as were the two aisle methods. The combined data from the two gutter methods were compared with the combined data from the two aisle methods. The main effects of method, house, date and season were analysed with several interactions and continuous-by-class variables. The data were also analysed by nesting season to remove the variation caused by this effect.

For each method, the proportion of the total number of flies recorded by that method during the entire study was calculated for each sampling time. The calculations were made for each of the five houses and for the data combined for all houses. The proportion of the total count for each sampling method for each house was plotted on each sampling date to illustrate the trends in seasonal abundance.

The square root transformed data for the visual resting count method were analysed with PROC GLM (SAS Institute, 1988) to determine if the number of replicates could be reduced to increase the practicality of sampling in this manner and to determine where the greatest numbers of resting flies were located.

\section{Results}

\section{Comparison of sampling methods}

All effects specified in the general linear models procedure were significant $(P=0.05)$ over all sampling dates except the gutter sampling methods (aspirator and ribbon) (F=0.89, df $=24, P=0.6217)$, and the aisle sampling methods (aisle ribbon and visual count) $(\mathrm{F}=1.38, \mathrm{df}=24$, $P=0.1112$ ). In this analysis, season was not used as a separate interaction but was nested within the date. When the combined data from the two aisle sampling methods were compared over all twenty-nine sampling dates with the combined data from the two gutter sampling methods, the differences were significant $(\mathrm{F}=9.43$, $\mathrm{df}=$ $24, P=0.0001)$. Also, the numbers of flies captured by the gutter sampling methods were generally higher than by the aisle sampling methods during the spring and summer, and lower during the autumn and winter.

The same results were obtained using the comparisons between each method alone without including the effects of date and season. With this analysis, the numbers of flies recorded by the two gutter sampling methods were not significantly different $(\mathrm{F}=1.00$, $\mathrm{df}=1, P=0.3368)$. Likewise, the number of flies recorded by the two aisle sampling methods were not significantly different $(\mathrm{F}=3.61$, df $=1, P=0.0819$ ). The combined data from the two gutter methods and from the two aisle methods differed significantly $(\mathrm{F}=23.34$, $\mathrm{df}=1, P=0.0004)$.

When the sampling methods were compared using season as an interaction, the two gutter sampling methods were not significantly different $(\mathrm{F}=0.54$, $\mathrm{df}=4, P=$ 0.7062 ), but the two aisle sampling methods were significantly different $(\mathrm{F}=3.88, \mathrm{df}=4, P=0.0070)$. The combined data from the two gutter sampling methods differed significantly $(P=0.05)$ from the combined data from the two aisle sampling methods $(\mathrm{F}=18.45$; $\mathrm{df}=4$, $P=0.0001)$.

In summary, based on these three analyses of the data, the results obtained by the two gutter sampling methods 

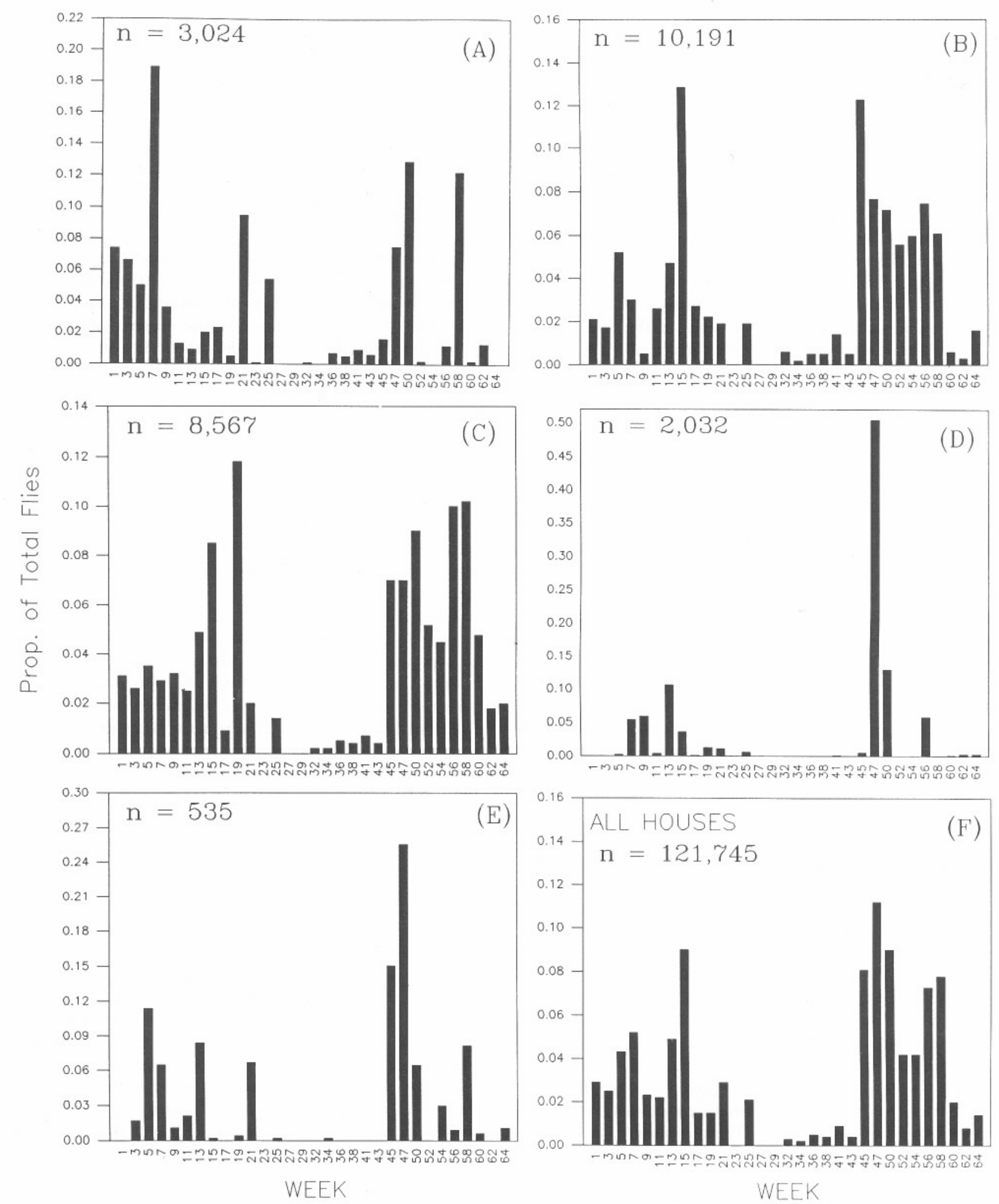

Fig. 5. Proportion of the total number $(n)$ of Drosophila repleta captured in the gutters by the aspirator method in five caged-layer poultry houses (A-E) and combined for all houses (F) during a 64-week period (5 June 1991 to 21 August 1992). 

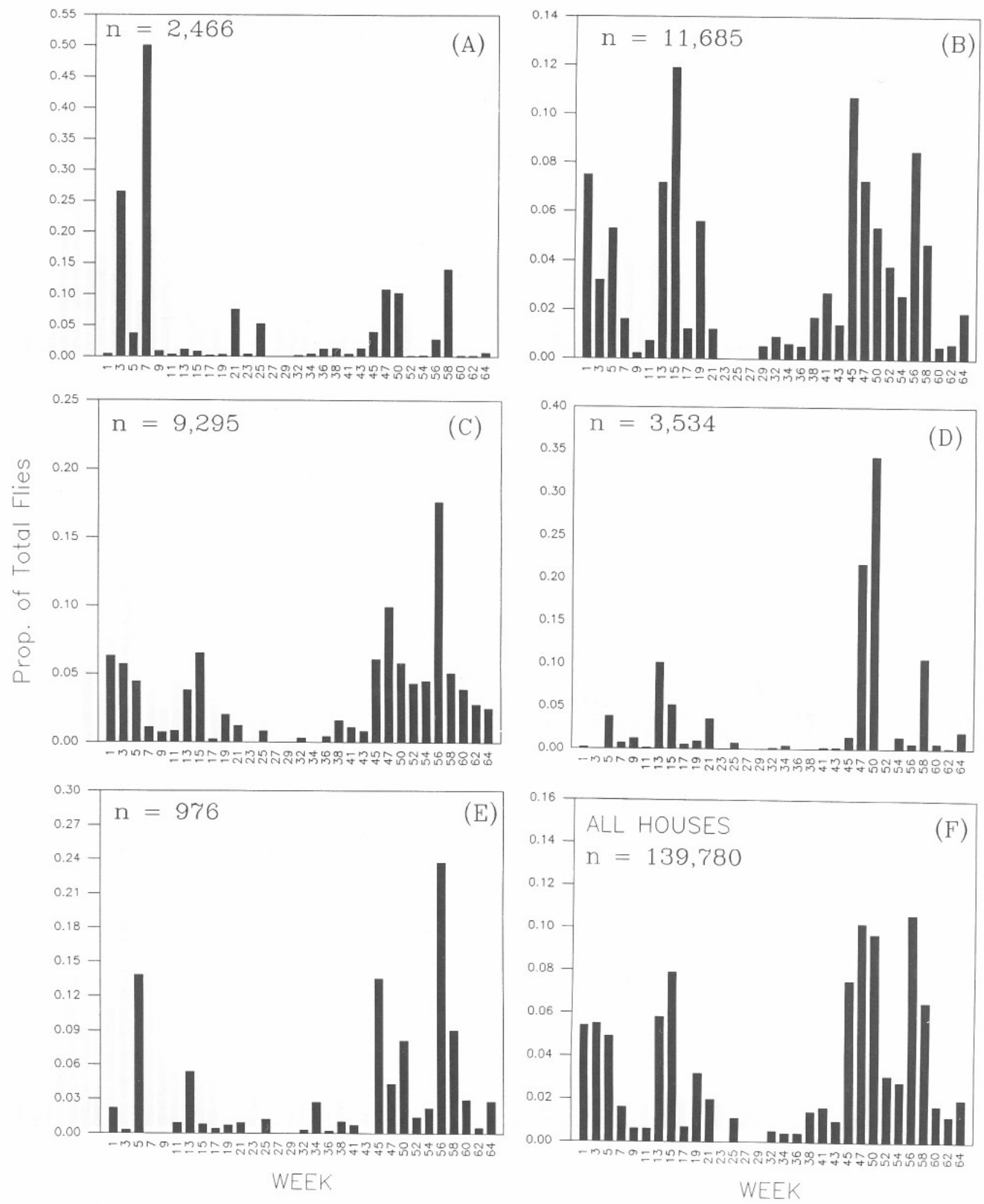

Fig. 6. Proportion of the total number ( $n$ ) of Drosophila repleta captured in the gutters with the ribbon method in five caged-layer poultry houses (A-E) and combined for all houses (F) during a 64-week period (5 June 1991 to 21 August 1992). 

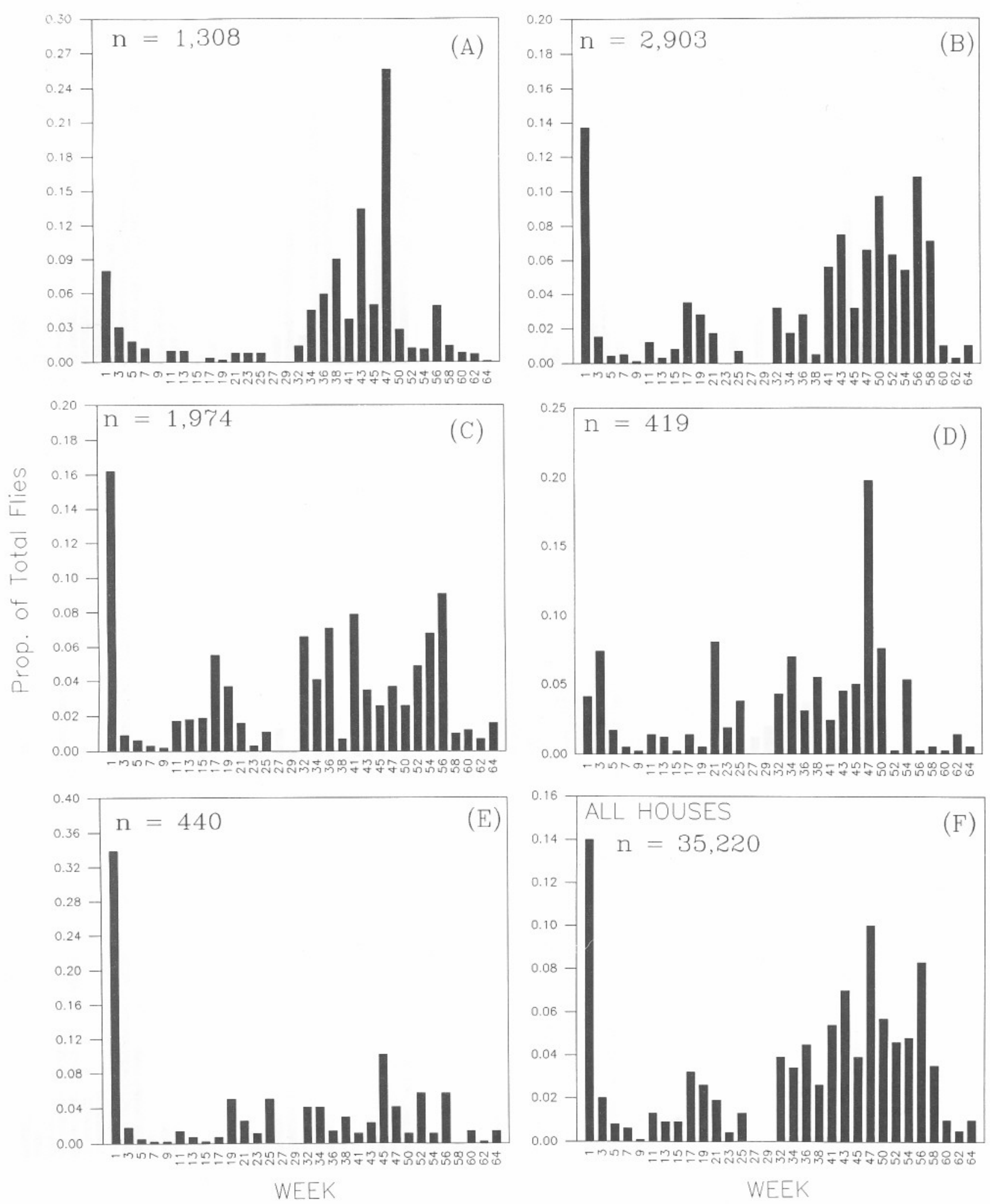

\section{WEEK}

Fig. 7. Proportion of the total number $(n)$ of Drosophila repleta captured in the gutters with the ribbon method in five caged-layer poultry houses (A-E) and combined for all houses (F) during a 64-week period (5 June 1991 to 21 August 1992). 

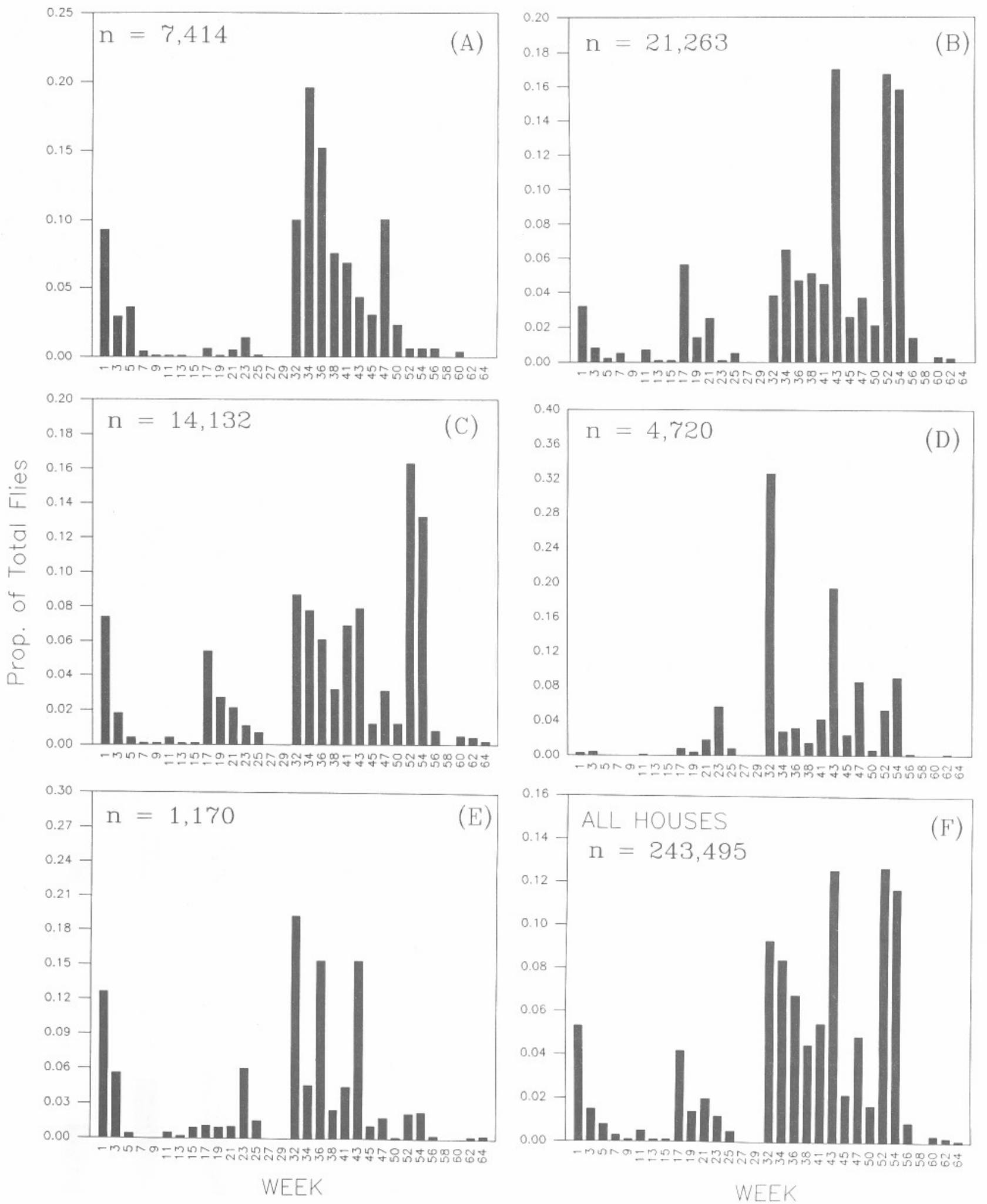

Fig. 8. Proportion of the total number $(n)$ of Drosophila repleta observed on the feed troughs by the visual resting count method in five caged-layer poultry houses (A-E) and combined for all house (F) during a 64-week period (5 June 1991 to 21 August 1992). 
(ribbon and aspirator) were not significantly different and the results from the two aisle sampling methods (ribbon and visual) were not significantly different over the entire sampling period. However, the combined data from the two gutter sampling methods differed significantly from the combined data from the two aisle sampling methods over the entire sampling period. When comparisons were made by season, the two aisle sampling methods were significantly different but the two gutter sampling methods were not.

\section{Seasonal abundance}

The proportions of D.repleta recorded by each sampling method for each sampling date at each house $(A-E)$ and combined for all houses (F) are provided in Figs 5-8. The houses varied in the dates when the highest proportion of flies were present. In week 47 (21 April), the highest proportion of flies were counted at houses A and D (Figs $5 \mathrm{~A}-8 \mathrm{~A}$ and $5 \mathrm{D}-8 \mathrm{D})$. For house $\mathrm{B}$, the highest proportion of flies were counted in week 45 (9 April) (Figs 5B-8B), and for house $\mathrm{C}$ in week 52 (29 May) (Figs 5C-8C). For house $\mathrm{E}$, the highest proportion of flies were counted in week 45 (9 April) and week 56 (25 June) (Figs 5E-8E). Although there were general trends in seasonal abundance, the actual numbers of flies varied greatly from house to house.

The variation in the proportions of flies indicated by the four different sampling methods during the different seasons are shown in Figs $5-8$. The seasonal populations represented by the gutter aspirator method (Fig. 5) and the gutter ribbon method (Fig. 6) were very similar; periods of high fly numbers occurred during weeks 1-7, 13-15 and 45-58. The walking aisle ribbon method (Fig. 7) showed periods of high fly numbers during week 1 , and weeks $41-56$. The visual resting counts (Fig. 8) showed periods of peak abundance during week 1 and weeks $32-54$. During the autumn and winter (weeks 17-43) the gutter sampling methods indicated low numbers of flies, whereas the walking aisle ribbon and the visual resting count indicated higher numbers. The visual resting count method recorded the greatest number of flies when the numbers indicated by the other three methods were very low.

Overall, periods of high Drosophila repleta incidence occurred from March to June, with slight peaks in late August and early September. Periods of low incidence occurred from October to March.

\section{Visual counts}

The results of the analysis of the visual resting count data indicated that house, aisle, feeder and site (location in the aisle) were significant $(\mathrm{F}=81.61$, $\mathrm{df}=4, P=0.0001$; $\mathrm{F}=11.82, \quad \mathrm{df}=1, \quad P=0.0006 ; \quad \mathrm{F}=97.21, \quad \mathrm{df}=1, \quad P=$ $0.0001 ; \mathrm{F}=22.45, \mathrm{df}=2, P=0.0001$, respectively). The combined interactions of aisle, feeder, house and site were significant $(\mathrm{F}=2.47, \mathrm{df}=44, P=0.0001)$. Season $(\mathrm{F}=$ $85.79, \mathrm{df}=2, P=0.0001)$, site by season $(\mathrm{F}=3.69, \mathrm{df}=4$,
$P=0.0005)$ and feeder by season $(\mathrm{F}=10.97, \mathrm{df}=2, P=$ $0.0001)$ were also significant.

The results of the second hypothesis test with the type III mean square for the combined interaction of house, aisle, site, feeder and season as the error term, showed that season $(\mathrm{F}=76.25$, $\mathrm{df}=2, P=0.0001)$ and feeder by season $(\mathrm{F}=9.75$, $\mathrm{df}=2, P=0.0001)$ were significant. It appears that these effects were significant even when the variability of house, aisle, site, feeder and season were removed. Due to the lack of significance of the aisle by feeder interaction $(\mathrm{F}=1.81$, $\mathrm{df}=1, P=0.1788)$, the aisle

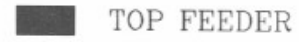

BOTTOM FEEDER
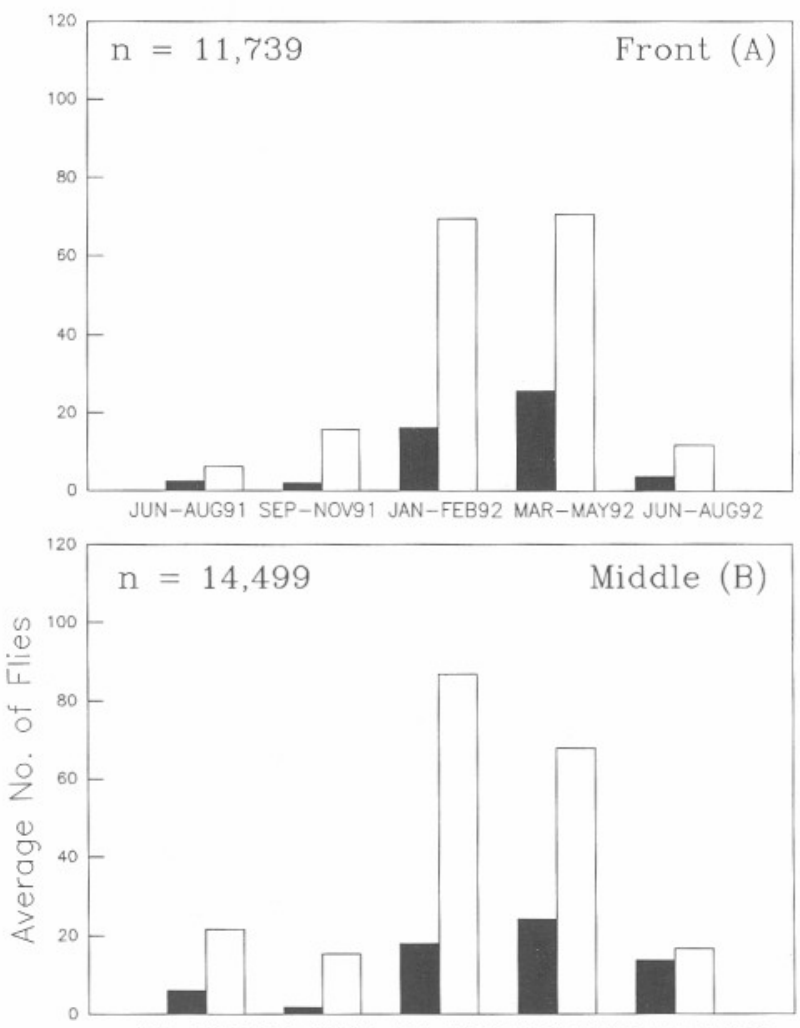

JUN-AUG91 SEP-NOV91 JAN-FEB92 MAR-MAY92 JUN-AUG92

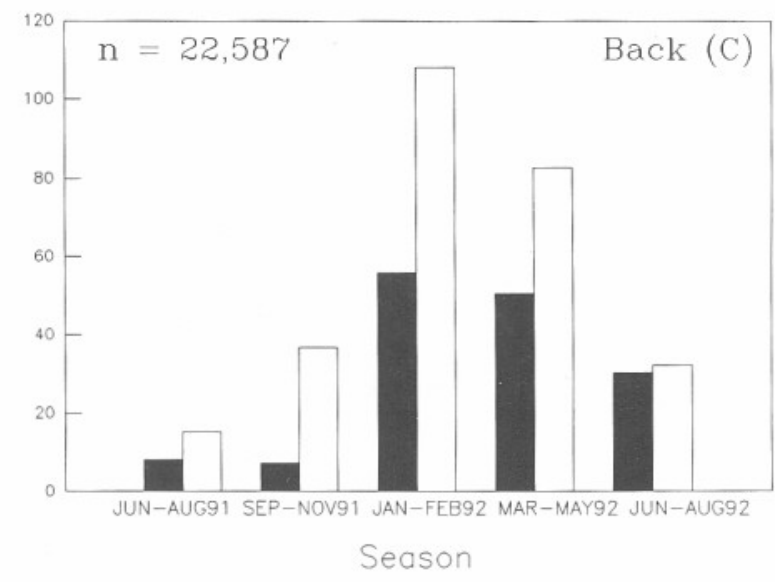

Fig. 9. Mean number of Drosophila repleta counted in a $3 \mathrm{~m}$ section of top ('upper') and bottom ('lower') feed troughs in the front, middle and back of two aisles in a caged-layer poultry houses based on the means per week for five houses calculated for five seasonal intervals during 5 June 1991 to 21 August 1992. 
in which the sampling was conducted did not appear to be important.

These analyses indicated that the feeder location (top versus bottom) was significant when sampling by the visual count method. Also, there was a strong feeder by season effect. The number of flies recorded on the top and bottom feeders differed significantly and changed with the time of year in which the sampling was conducted. Plots of the mean for each season for the front, middle, and back of the two aisles are shown in Fig. 9. The greatest number of flies were recorded with the visual resting count method during the winter (January and February) and the second highest number in the spring (March-May). Mean counts of Drosophila were greater on the bottom feeders than the top feeders in both aisles and in all parts (front, middle, back) of an aisle.

The location in the house (either the front, middle or back) was significant as demonstrated with the site by season interaction $(\mathrm{F}=3.28, \mathrm{df}=4, P=0.0144)$. The mean counts of resting flies were highest in the back portion of the aisles (Fig. 9C).

\section{Discussion}

The results obtained using the aspirator method and the ribbon method to sample the gutter were not significantly different; therefore using both methods would be redundant. The gutter ribbon method is the more practical of the two gutter sampling methods; it is less expensive, easier, and faster to use than the aspirator method. High numbers of flies were captured with this method.

The aisle ribbon method is much less practical than the visual counts. It involves a considerable amount of time walking slowly up and down the aisles of the houses. The visual count of flies resting on the feed troughs method is quick and simple to use.

The visual resting count method appears to be the most practical of the four sampling methods. Although the number of flies counted on the top and bottom feeders and in different locations in the house were significantly different, the counts followed the same pattern (Fig. 9). The seasonal population pattern could be adequately monitored by counting the numbers of flies only in the front part of the aisles; the front of the house is easier to reach than the back. Although the numbers of flies would be lower than counts in the back of the house, they would still reflect changes in population activity. Counting the number of flies resting on a $3 \mathrm{~m}$ section of feeder for the top and bottom feeder in two inside aisles in the front of the houses would be adequate.

Undoubtedly, D.repleta is the dominant fruit fly species in caged-layer poultry houses. Only seven specimens of other species were collected during this study; five were D. funebris Fabricius and two were D.melanogaster Meigen. Drosophila repleta may also be a pest in turkey and swine houses; we recovered it from traps in hog and turkey houses in Duplin County, North Carolina, during JuneAugust 1992.
Based on our findings, the visual resting count method is the most practical for use in routine monitoring of D.repleta populations as part of a filth-fly management programme. This method is sensitive to population changes and is especially useful for monitoring the adult Drosophila population during periods of low activity. We suggest counting the resting flies on a $3 \mathrm{~m}$ section of an upper and a lower feeder in two inside rows in the front part of a caged-layer house at weekly intervals. If possible, the visual counts should be supplemented with counts by the gutter ribbon method which samples a different area of the house and may provide an earlier warning of a problem.

\section{Acknowledgments}

The research in this publication was funded in part by the North Carolina Agricultural Research Service and the USDA-Cooperative States Research Service Agreement No. 90-34103-4982. The use of trade names in this publication does not imply endorsement by the North Carolina Agricultural Research Service, nor criticism of similar ones not mentioned. The authors thank Dr Cavell Brownie for assistance with the statistical analyses and $\mathrm{Mr}$ Greg Burke for assistance in the sampling.

\section{References}

Farkas, R. \& Papp, L. (1989) Species composition and breeding sites of fly communities (Diptera) in caged-layer houses in Hungary. Parasitologia Hungarica, 22, 93-97.

Kuhlhorn, F. (1964) Uber die Dipterenfauna des Stallbiotops. Beitrage zur Entomologie, 14, 85-118.

Papp, L. (1974) Dipterological studies in some Hungarian largescale pig farms. Acta Agronomica Academiae Scientiarum Hungaricae, 23, 136-147.

Patterson, J.T. \& Mainland, G.B. (1944) Studies in the genetics of Drosophila. The Drosophilidae of Mexico. The University of Texas Publications, 4445, (4), 17-24.

Perdew, P.E. \& Meek, C.L. (1990) An improved model of a battery-powered aspirator. Journal of the American Mosquito Control Association, 6, 716-719.

Ribbeck, R., Betke, P., Muller, P., Schumann, H. \& Hiepe, T. (1987) Stallfliegen-schadwirkung und Bekampfung in der Intensiventeirproduktion. Monatshefte für Veterinarmedizin, 42, $517-521$.

SAS Institute (1988) SAS/STAT User's Guide, Release 6.03 Edition. SAS Institute, Cary, North Carolina, U.S.A.

Strickberger, M.W. (1962) Keys to the U.S. species of Drosophila. Experiments in the Genetics of Drosophila, pp. 111-123. Wiley \& Sons, New York.

Turner, E.C. \& Ruszler, P.L. (1989) A quick and simple quantitative method to monitor house fly populations in caged layer houses. Poultry Science, 68, 833-835.

Wollaston, T.V. (1858) Brief diagnostic characters of undescribed Madieran insects. Annals and Magazine of Natural History, 41, 117.

Accepted 17 November 1993 